\title{
ИНТЕГРАЦИОННОЕ ПРАВО
}

DOI: 10.17803/1994-1471.2020.111.2.166-174

М. Е. Садомовская*

\section{Эволюция правовых основ Европейского Союза в сфере противодействия легализации (отмыванию) доходов, полученных преступным путем, и финансированию терроризма: современные тенденции и перспективы}

\begin{abstract}
Аннотация. В настоящее время в Европейском Союзе существует развитый режим противодействия легализации (отмыванию) доходов, полученных преступным путем, и финансированию терроризма. На протяжении почти 30 лет существования данный режим доказал свою эффективность в достижении поставленных целей благодаря всеобъемлющему характеру регулирования и соответствию мировым достижениям в сфере противодействия легализации доходов, полученных преступным путем, и финансированию терроризма, в первую очередь рекомендациям Группы разработки финансовых мер по борьбе с отмыванием денег (ФАТФ). Разработанный европейским законодателем режим ПОД/ФТ стал результативным инструментом борьбы с легализацией преступных доходов в условиях, когда данная проблема встала особенно остро в связи с повсеместным ужесточением мер борьбы с терроризмом, в том числе международным. Именно по этой причине европейский режим ПОД/ФТ послужил ориентиром при разработке «антиотмывочных» мер многих государств, не входящих в состав Европейского Союза, в том числе Российской Федерации. В статье рассмотрено содержание актуальных тенденций правового регулирования Европейского Союза в сфере противодействия легализации доходов, полученных преступным путем, и финансированию терроризма, а также дан обзор основных перспектив и направлений развития.

Ключевые слова: интеграционное право; право Европейского Союза; Европейский Союз; ЕС; противодействие легализации доходов, полученных преступным путем; противодействие финансированию терроризма; ПОД/ФТ; идентификация клиентов; финансовый мониторинг; бенефициарный владелец.

Для цитирования: Садомовская М. Е. Эволюция правовых основ Европейского Союза в сфере противодействия легализации (отмыванию) доходов, полученных преступным путем, и финансированию терроризма: современные тенденции и перспективы // Актуальные проблемы российского права. - 2020. - Т. 15. № 2. - C. 166-174. - DOI: 10.17803/1994-1471.2020.111.2.166-174.
\end{abstract}

(C) Садомовская М. Е., 2020

* Садомовская Мария Евгеньевна, аспирант Московского государственного юридического университета имени О.Е. Кутафина (МГЮА)

Садовая-Кудринская ул., д. 9, г. Москва, Россия, 125993

m.sadomovskaya@yandex.ru 


\title{
The Evolution of Legal Foundations of the European Union in the Field of Combating Legalization (Laundering) of Proceeds from Crime and Financing of Terrorism: Current Trends and Prospects
}

\author{
Maria E. Sadomovskaya, Postgraduate student of Kutafin Moscow State Law University (MSAL) \\ ul. Sadovaya-Kudrinskaya, d. 9, Moscow, Russia, 125993 \\ m.sadomovskaya@yandex.ru
}

\begin{abstract}
Currently, the European Union has a developed regime for counteracting the legalization (laundering) of proceeds from crime and the financing of terrorism. Over the nearly 30 years of its existence, this regime has proven to be effective in achieving its goals thanks to the comprehensive nature of regulation and compliance with international achievements in the field of combating money laundering and the financing of terrorism, primarily the recommendations of the Financial Action Task Force on Money Laundering (FATF). The AML / CFT regime developed by the European legislator has become an effective tool for combating money laundering in conditions when this problem turned to be acute due to the widespread tightening of counter-terrorism measures, including international ones. It is for this reason that the European AML / CFT regime has served as a guideline in the development of "anti-laundering" measures of many states that are not members of the European Union, including the Russian Federation. The paper discusses the content of current trends in the legal regulation of the European Union in the field of combating money laundering and the financing of terrorism, as well as an overview of the main development prospects and directions.

Keywords: integration law; European Union law; European Union; EU; countering legalization of proceeds of crime; countering the financing of terrorism; AML / CFT; customer identification; financial monitoring; beneficial owner. Cite as: Sadomovskaya ME. Evolyutsiya pravovykh osnov evropeyskogo soyuza v sfere protivodeystviya legalizatsii (otmyvaniyu) dokhodov, poluchennykh prestupnym putem, i finansirovaniyu terrorizma: [The evolution of legal foundations of the European Union in the field of combating legalization (laundering) of proceeds from crime and financing of terrorism: Current trends and prospects]. Aktualnye problemy rossiyskogo prava. 2020;15(2):166-174. DOI: 10.17803/1994-1471.2020.111.2.166-174. (In Russ., abstract in Eng.).
\end{abstract}

\section{Введение}

За менее чем 30 лет в Европейском Союзе был разработан эффективный режим противодействия легализации (отмыванию) доходов, полученных преступным путем, и финансированию терроризма (далее - ПОД/ФТ), в значительной мере послуживший ориентиром для российского законодателя при разработке режима ПОД/ ФТ, действующего в настоящее время в Российской Федерации.

Европейский режим ПОД/ФТ включает в себя два ключевых аспекта ${ }^{1}$ : запрет легализации преступных доходов и финансирования терроризма, а также предотвращение легализации таких доходов путем возложения ряда обязанностей на так называемых обязанных субъектов. В настоящей статье будут рассмотрено содержание ключевых современных тенденций правового регулирования Европейского Союза в сфере ПОД/ФТ в контексте указанных выше аспектов.

Тема статьи приобретает особую значимость в свете повсеместного ужесточения мер борьбы с терроризмом, в том числе международным. Европейский законодатель стремится обеспечить эффективность европейского режима ПОД/ ФТ и его соответствие международным стандартам в названной сфере, в том числе Рекомендациям ФАТФ, понимая, что меры, принятые лишь на национальном уровне или даже только на

1 Borlini L., Montanaro F. The Evolution of the EU law against criminal finance: the "hardening» of FATF Standards within EU // Georgetown Journal of International Law. 2017 ; Bocconi Legal Studies Research Paper No. 3010099. P. 1030. 
уровне Союза, без учета международной координации и сотрудничества, будут менее результативными².

\section{1. Новый базовый документ Европейского Союза в сфере противодействия легализации доходов, полученных преступным путем, и финансированию терроризма}

Предпосылкой для внесения изменений в европейский режим ПОД/ФТ в очередной раз стало принятие новой редакции рекомендаций ФАТФ в 2012 г., а также стремление европейского законодателя восполнить пробелы в регулировании, нашедшие отражение в отчете об имплементации Директивы 2005/60/EC ${ }^{3}$. В преамбуле новой Директивы 2015/849 прямо установлено, что в целях повышения эффективности борьбы с легализацией доходов, полученных преступным путем, и финансированием терроризма соответствующие правовые акты Союза должны быть совместимы с Международными стандартами по борьбе с отмыванием денег и финансированием терроризма и распространения оружия массового уничтожения, принятыми ФАТФ в феврале 2012 г.

Директива 2015/8494, вступившая в силу 26 июня 2015 г. и заменившая Директиву 2005/60/ЕС, существенным образом расширила сферу действия европейских требований ПОД/ ФТ как за счет дополнения перечня предикатных преступлений (в него были включены налоговые преступления), так и за счет расширения круга лиц, операции которых подлежат особому контролю со стороны обязанных субъектов (к ним были отнесены политически значимые лица, например главы государств, главы правительств, министры и заместители министров).
В рамках нового режима ПОД/ФТ центральная роль отводится принципу анализа рисков и гарантиям, направленным на минимизацию таких рисков. Так, Директива предусматривает три уровня оценки риска отмывания доходов / финансирования терроризма (ОД/ФТ).

Во-первых, в соответствии с требованиями Директивы 2015/849 Европейская комиссия проводит оценку рисков ОД/ФТ, влияющих на внутренний рынок и относящихся к трансграничной деятельности, и готовит по результатам оценки отчет, который подлежит актуализации каждые два года или чаще в случае необходимости. Такой отчет должен как минимум определять секторы внутреннего рынка, подверженные наибольшему риску; риски, присущие каждому сектору, а также наиболее распространенные механизмы, используемые преступниками для легализации доходов, полученных преступным путем. Европейская комиссия обязана предоставлять данный отчет государствам-членам и обязанным субъектам с тем, чтобы содействовать им в управлении рисками ОД/ФТ. Кроме того, Комиссия уполномочена направлять в государства-члены рекомендации о мерах, которые необходимо принять для устранения выявленных рисков, однако государства-члены вправе не следовать рекомендациям Комиссии.

Во-вторых, каждое государство - член ЕС принимает меры для выявления, оценки, понимания и снижения влияющих на него рисков ОД/ФТ. При проведении оценки необходимо учитывать данные отчета Европейской комиссии. Государство - член ЕС должно учитывать результаты оценки присущих ему рисков ОД/ФТ при совершенствовании своего режима ПОД/ ФТ, в частности за счет выявления сфер, в отно-

2 Perula J. The European Union's anti-money laundering crusade - a critical analysis of the responses by the EU/EC to money laundering // Reports of the Police College of Finland 83/2019. Tampere. 2009. P. 37.

3 Report from the Commission to the European Parliament and the Council on the application of Directive 2005/60/EC on the prevention of the use of the financial system for the purpose of money laundering and terrorist financing, COM/2012/0168 final.

4 Directive (EU) 2015/849 of the European Parliament and of the Council of 20 May 2015 on the prevention of the use of the financial system for the purposes of money laundering or terrorist financing, amending Regulation (EU) No 648/2012 of the European Parliament and of the Council, and repealing Directive 2005/60/EC of the European Parliament and of the Council and Commission Directive 2006/70/EC // OJ L 141. 05.06.2015. Pp. 73-117. 
шении которых обязанные субъекты должны применять повышенные меры, обеспечения разработки надлежащих правил для каждого сектора или области с учетом риска ОД/ФТ и т.д. Государства - члены ЕС направляют результаты своей оценки рисков Европейской комиссии, европейским органам финансового надзора (ESMA, EBA, EIOPA) и другим государствам членам ЕС.

Наконец, государства-члены обязаны предусмотреть в национальном законодательстве обязанность обязанных субъектов по выявлению и оценке риска ОД/ФТ с учетом факторов риска, связанных с их клиентами, странами или географическими районами, продуктами, услугами, сделками или каналами поставки. При этом обязанным субъектам следует принимать меры по устранению трех уровней риска: общеевропейских исков, отраженных Комиссией в отчете; рисков, выявленных государством-членом и рисков, идентифицированных самим обязанным субъектом применительно к его деятельности. Такие меры должны включать, в частности, разработку внутренних стратегий, мер контроля и процедур, мер по проверке клиентов, систем отчетности, внутреннего контроля, назначение специалиста по обеспечению нормативно-правового соответствия на уровне управления, а также независимый аудит для проверки указанных внутренних стратегий, мер контроля и процедур.

Другим существенным нововведением Директивы 2015/849 стало то, что государствам членам ЕС предписано предусмотреть в национальном законодательстве обязанность корпоративных и иных юридических лиц, созданных на их территории, вести учет бенефициарных владельцев. Юридические лица обязаны получать и хранить достаточную, точную и актуальную информацию о бенефициарных владельцах, включая подробные сведения о принадлежащих им долях в таких юридических лицах. Указанную информацию юридические лица обязаны раскрывать обязанным субъектам в ходе проводимой ими проверки, а также предоставлять доступ к такой информации национальным уполномоченным органам и органам финансового мониторинга. Аналогичные обязанности должны быть возложены на доверительных собственников трастов, которым следует хранить актуальную информацию о личности учредителя траста, о его доверительных собственниках, попечителе траста, лицах, в интересах которых учрежден траст, а также о любом другом физическом лице, осуществляющем фактический контроль над трастом.

Государства-члены также обязаны гарантировать, что указанная выше информация о бенефициарных владельцах содержится в центральном реестре - будь то торговый реестр, реестр компаний или специально созданная для этой цели база данных. В такой реестр или базу данных также включается информация о бенефициарных владельцах трастов, деятельность которых порождает налоговые последствия. Доступ к такой информации осуществляется на трех уровнях. Полный и неограниченный доступ ко всей информации имеют уполномоченные органы и органы финансового мониторинга. Обязанным субъектам такая информация доступна только в рамках проверки клиента. Доступ к информации о бенефициарных владельцах также может быть предоставлен любому лицу или организации, доказавшим наличие законного интереса. При этом последним доступна лишь минимальная информация о бенефициарных владельцах: имя, дата рождения, гражданство и страна проживания, характер и размер доли. Доступ к информации о бенефициарных владельцах предоставляется в соответствии с нормами о защите данных и может предусматривать регистрацию на сайте и уплату пошлины.

Стремясь соответствовать Рекомендациям ФАТФ в части повышения прозрачности и открытости данных о бенефициарных владельцах, Директива также предусматривает, что уполномоченные органы и органы финансового мониторинга могут обмениваться такой информацией с уполномоченными органами и органами финансового мониторинга других государств-членов.

Директива 2015/849 во многих аспектах ужесточила требования по сравнению с ранее действовавшим режимом ПОД/ФТ. В частности, с 15000 евро до 10000 евро был снижен порог для операций с наличными денежными сред- 
ствами, при проведении которых лица, торгующие товарами, обязаны проводить проверку клиента. Более того, государствам - члены ЕС предоставлено право устанавливать более низкие пороговые значения, дополнительные общие ограничения на использование наличных средств, а также дополнительные более строгие положения. Директивой в круг обязанных субъектов были включены поставщики услуг, связанных с азартными играми. Государства-члены вправе, однако, исключить организаторов азартных игр, кроме казино, полностью или частично из круга обязанных субъектов, если их деятельность предполагает низкий уровень риска ОД/ФТ.

Хотя уже в соответствии с ранее действовавшими европейскими требованиями в сфере ПОД/ФТ банки и некоторые другие компании финансового сектора обязаны были создавать системы соответствия в рамках всей группы (банковской группы или финансового холдинга), включая требования должной осмотрительности в отношении риска легализации денежных средств, эта обязанность в соответствии с Директивой 2015/846 также распространяется на других обязанных субъектов: на филиалы и дочерние компании, находящиеся в мажоритарной собственности обязанных субъектов и расположенные на территории государств, не являющихся членами ЕC.

Положения Директивы, касающиеся проверки клиентов, не претерпели коренных изменений: в большинстве своем требования Директивы 2015/849, по существу, повторяют аналогичные требования ранее действовавшей Директивы 2005/60/ЕС. При этом новая Директива определяет ряд переменных показателей риска, которые необходимо учитывать при оценке риска ОД/ФТ при решении вопроса о том, какую проверку - стандартную, усиленную или упрощенную - необходимо провести в отношении клиента. К таким факторам относятся цель открытия счета или установления отношений, объем активов, депонируемых клиентом, или размер совершаемых операций, а также систематичность или продолжительность деловых отношений.
Директива 2015/849 определяет также ряд факторов и потенциальных доказательств низкого риска ОД/ФТ, при наличии которых обязанный субъект может провести упрощенную проверку. Эти факторы делятся на три группы: факторы риска, относящиеся к клиенту (публичные компании, котирующиеся на фондовых биржах, к которым предъявляются требования о раскрытии информации), факторы риска, связанные с продуктами, услугами, сделками или каналами поставки (полисы страхования жизни, страховая премия по которым незначительна) и географические факторы риска (государства члены Союза). Аналогичным образом Директива устанавливает такие же группы факторов риска, позволяющие сделать вывод о повышенном уровне риска ОД/ФТ, при наличии которого в отношении клиента проводится усиленная проверка.

Что касается санкций, Директива 2015/849 следует подходу, характерному для европейского законодательства последних лет. Он предполагает конкретные широкие полномочия государств-членов в части применения мер ответственности к лицам, допускающим нарушения требований Директивы. Так, государства-члены должны гарантировать, что в случае серьезных, повторяющихся или систематических несоблюдений обязанными субъектами определенных ключевых требований Директивы (непроведение надлежащей проверки клиента, неисполнение обязанности по направлению информации о подозрительной сделке) к последним будут применены строгие меры ответственности, например административные денежные санкции в размере, как минимум в 2 раза превышающем размер выгоды, полученной в результате нарушения, если такая выгода может быть определена, или как минимум 1000000 евро. При этом для банков и других поставщиков финансовых услуг максимальный размер административного штрафа составляет 5000000 евро или 10 \% от общего годового оборота по данным последней имеющейся отчетности, одобренной органом управления. 


\section{2. Последние изменения}

европейского режима противодействия легализации преступных доходов и финансированию терроризма

Директива Европейского Парламента и Совета 2018/8435 от 30 мая 2018 г., вносящая изменения в Директиву 2015/849, вступила в силу 9 июля 2018 г. Новый документ вносит немногочисленные изменения в предыдущую редакцию Директивы, однако с точки зрения их содержания эти изменения существенным образом расширяют сферу действия Директивы.

Прежде всего, в очередной раз был расширен круг обязанных субъектов. Данное изменение связано со стремлением Европейского Союза минимизировать риски ОД/ФТ, связанные с использованием криптовалют ${ }^{6}$ и виртуальной валюты ${ }^{7}$. По этой причине в круг обязанных субъектов были включены поставщики услуг, деятельность которых связана с обменом виртуальной валюты на фиатную валюту ${ }^{8}$, поставщики электронных кошельков, лица, торгующие или действующие в качестве посредников в торговле произведениями искусства, если стоимость сделки или серии связанных сделок составляет 10000 евро или более, а также лица, осуществляющие хранение, торговлю или действующие в качестве посредников в торговле произведениями искусства, когда эта торговля осуществляется свободными портами, если стоимость транзакции или серии связанных транзакций составляет 10000 евро.

Новая Директива уточнила порядок взаимодействия с клиентами, происходящими из не входящих в ЕС государств, которым Европейской комиссией был присвоен повышенный уровень риска. Предыдущая редакция Директивы предусматривала, что в отношении такого рода клиентов должна проводиться усиленная провер- ка, не определяя конкретные меры. Директива 2018/843 восполняет этот пробел, устанавливая, что применительно к таким клиентам усиленная проверка должна включать в себя меры по получению дополнительной информации о клиенте и его бенефициарных владельцах, о предполагаемом характере деловых отношений, об источнике средств клиента и его бенефициарных владельцев. На установление деловых отношений с клиентом из страны с повышенным уровнем риска, по условиям Директивы, должно быть получено согласие руководства обязанного субъекта.

Наиболее существенной и неоднозначной новеллой Директивы в новой редакции стало изменение режима доступа к информации о бенефициарных владельцах. Предыдущая редакция Директивы предусматривала, что доступ к указанной информации может получить любое лицо или организация, если докажет наличие законного интереса. По новым правилам информация о бенефициарных владельцах стала открытой. Вводя эту норму, европейский законодатель исходил из того, что открытость информации о бенефициарных владельцах обеспечит бо́льшую прозрачность совершаемых операций, позволит институтам гражданского общества и средствам массовой информации осуществлять контроль за операциями на финансовом рынке. Такой подход призван также способствовать борьбе с неправомерным использованием корпоративных и иных юридических лиц, а также структур без образования юридического лица для целей ОД/ФТ, как за счет содействия проводимым расследованиям, так и за счет репарационного аспекта (для лица, потенциально заключающего сделку, личность бенефициарного владельца не будет секретом).

5 Directive (EU) 2018/843 of the European Parliament and of the Council of 30 May 2018 amending Directive (EU) 2015/849 on the prevention of the use of the financial system for the purposes of money laundering or terrorist financing, and amending Directives 2009/138/EC and 2013/36/EU // OJ L 156. 19.06.2018. Pp. 43-74.

6 Haffke L., Fromberger M., Zimmermann P. Cryptocurrencies and anti-money laundering: the shortcomings of the fifth AML Directive (EU) and how to address them // Journal of Banking Regulation. 2019. P. 2

7 European Commission. (2018) Strengthened EU rules to prevent money laundering and terrorism financing Fact Sheet. 9 July // URL: www.europa.eu/rapid/press-release_STATEMENT-18-3429_en.html (дата обращения: 23.06.2019).

8 Валюта, которую государство объявляет в качестве законного платежного средства. 
Однако необходимо учитывать, что неопределенному кругу лиц доступна минимальная информация о бенефициарных владельцах: имя, дата рождения, гражданство и страна проживания, характер и размер доли. Однако государства - члены ЕС вправе предусмотреть в национальном законодательстве возможность получать доступ к дополнительной информации, например к контактным данным бенефициарного владельца при соблюдении требований в части защиты данных.

\section{3. Гармонизация уголовного} законодательства государств - членов ЕС
в области противодействия легализации
доходов, полученных преступным путем

Директива 2018/16739 вступила в силу в декабре 2018 г. и ознаменовала новый виток развития европейского режима ПОД/ФТ. Новая Директива пришла на смену Рамочному решению 2001/500/ПВД от 26 июня 2001 г. $^{10}$, которое утратило свою актуальность как в свете развития правового регулирования ЕС в сфере ПОД/ФТ, так и в связи с отменой системы трех опор - в рамках третьей опоры (СПСО - сотрудничество полицейских и судебных органов государств в уголовно-правовой сфере) было принято Рамочное решение - после вступления в силу Лиссабонского договора. Новая же Директива была принята на основании ст. 83 Договора о функционировании Европейского Союза (ДФЕС) ${ }^{11}$ в редакции Лиссабонского договора, которая предусматривает, что Европейский Парламент и Совет в рамках обычной законодательной процедуры могут принимать директивы, устанавливающие минимальные правила определения преступлений и мер ответственности в отношении особо тяжких преступлений, имеющих трансграничный масштаб, обусловленный характером или последствиями таких преступлений или же необходимостью бороться с ними на общих началах. В соответствии с указанной статьей ДФЕС к такого рода преступлениям, помимо прочих, относится легализация доходов, полученных преступным путем.

Соответственно, главная задача Директивы 2018/1673 сводится к установлению единообразных мер ответственности за преступления в сфере ПОД/ФТ. Для этих целей Директива в первую очередь определяет общий для всех государств - членов ЕС перечень предикатных преступлений. В Директиве предусмотрен двухуровневый подход к определению предикатного преступления. Во-первых, к таким преступлениям относятся любое преступное участие в совершении любого преступления, за которое национальным законодательством установлены меры ответственности в виде лишения свободы или заключения под стражу на срок более одного года или, если речь идет о государствах-членах, в которых установлен минимальный порог для преступлений, любое правонарушение, за которое национальным законодательством установлены меры ответственности в виде лишения свободы или заключения под стражу на срок не менее 6 месяцев. Во-вторых, Директива перечисляет 22 категории преступлений, которые государства-члены должны рассматривать в качестве предикатных преступлений. Указание на многие из этих 22 категорий преступлений, к которым, в частности, относятся торговля людьми, незаконная торговля оружием, коррупция, незаконная торговля наркотическими и психотропными веществами, также содержится в ст. 83 ДФЕС, ст. 3 Директивы 2015/849 и других актах ЕС.

Директива также содержит указание на те действия, которые, будучи совершенными умышленно, составляют легализацию доходов, полученных преступным путем. Данное определение существенным образом не отличается от определения, данного в Директиве 2015/849. Однако необходимо заметить, что помощь и содействие в совершении преступления по

9 Directive (EU) 2018/1673 of the European Parliament and of the Council of 23 October 2018 on combating money laundering by criminal law // OJ L 284. 12.11.2018. Pp. 22-30.

10 Council Framework Decision of 26 June 2001 on money laundering, the identification, tracing, freezing, seizing and confiscation of instrumentalities and the proceeds of crime // OJ L 182. 05.07.2001. Pp. 1-2.

11 Consolidated version of the Treaty on the Functioning of the European Union // OJ C 326. 26.10.2012. Pp. 47-390. 
легализации преступных доходов выделены в отдельный состав.

Значимой новеллой стало установление обязанности государств-членов рассматривать в качестве преступления в сфере ОД/ФТ легализацию собственных доходов (в английском варианте - self-laundering). Такого рода преступление имеет место тогда, когда действия, направленные на легализацию преступных доходов, совершает лицо, совершившее предикатное преступление.

Директива существенно упрощает привлечение к ответственности за легализацию доходов, полученных преступным путем, исключив действие определенных факторов, которые могут стать преградой привлечению к ответственности. Так, Директива предусматривает, что привлечение к ответственности за легализацию возможно без предварительного или одновременного привлечения к ответственности за совершение предикатного преступления, без установления всех фактических обстоятельств совершенного предикатного преступления (включая личность преступника), а также вне зависимости от того, было ли предикатное преступление совершено на территории другого государства.

Что касается мер ответственности за легализацию преступных доходов, Директива 2018/1673 обязывает государства-члены предусмотреть в качестве наиболее суровой меры заключение под стражу на срок не менее 4 лет. Кроме того, государства-члены обязаны определить дополнительные меры ответственности, подлежащие применению к физическим лицам, такие как штраф, временный запрет на выдвижение на выборную или государственную должность и т.д. Директива также устанавливает отягчающие обстоятельства, которые соответствующие органы государств-членов должны учитывать при вынесении приговоров. Например, отягчающим обстоятельством является совершение преступления по легализации преступных доходов обязанным субъектом по смыслу Директивы 20015/849. Определенная свобода усмотрения в части определения отягчающих обстоятельств предоставлена и государствам-членам: они вправе рассматривать в качестве отягчающего обстоятельства стоимость отмываемого имущества или характер предикатного преступления.

Наконец, Директива 2018/1673 закрепляет четкие правила определения юрисдикции государств-членов в отношении совершенных преступлений в сфере ОД/ФТ. Так, по умолчанию под юрисдикцию государства - члена ЕС подпадают преступления, совершенные на его территории, а также преступления, совершенные его гражданами. Государство-член, уведомив об этом Европейскую комиссию, также может расширить свою юрисдикцию за счет преступлений, совершенных лицом, постоянно проживающим на территории такого государства-члена, а также за счет преступлений, совершенных в интересах юридического лица, созданного на территории государства-члена. Если же преступление в равной мере подпадает под юрисдикцию нескольких государств-членов, последние обязаны совместными усилиями определить, какое из них будет осуществлять преследование за его совершение. При этом государства-члены обязаны учитывать страну гражданства или проживания преступника, страну происхождения жертвы, а также то, на территории какого государства было совершено преступление и на территории какой страны был задержан преступник.

Положения Директивы 2018/1673 существенным образом дополняют европейский режим ПОД/ФТ, основой которого в настоящее время служит Директива 2015/849 в редакции Директивы 2018/843, учитывающая, в свою очередь, все достижения предыдущих этапов развития правового регулирования ПОД/ФТ в Европейском Союзе. Директива 2018/1673 также способствует укреплению мер ЕС по созданию Союза безопасности, который включает в себя меры по борьбе как с финансированием терроризма, так и с финансовыми преступлениями.

\section{Заключение}

На протяжении почти 30 лет развития европейский режим ПОД/ФТ претерпел существенные изменения. В последние годы развитие правового регулирования ПОД/ФТ в Европейском Союзе развивалось особенно активно: менее чем за 5 лет было разработано 3 законодатель- 
ных акта, внесших коренные изменения в существовавший ранее режим ПОД/ФТ. Правовое регулирование ЕС в сфере ПОД/ФТ на протяжении всей истории своего развития стремится к достижению двух ключевых целей: предотвращению использования финансовой системы для финансирования преступной деятельности и укреплению правил прозрачности для предотвращения крупномасштабного сокрытия средств. Принимаемые ЕС меры направлены на то, чтобы лица, стремящиеся легализовать доходы, полученные преступным путем, были лишены возможности воспользоваться в этих целях достижениями Европейского Союза.

\section{БИБЛИОГРАФИЯ}

1. Borlini L., Montanaro F. The Evolution of the EU law against criminal finance: the "hardening» of FATF Standards within EU // Georgetown Journal of International Law, 2017; Bocconi Legal Studies Research Paper No. 3010099.

2. Haffke L., Fromberger M., Zimmermann P. Cryptocurrencies and anti-money laundering: the shortcomings of the fifth AML Directive (EU) and how to address them // Journal of Banking Regulation, 2019.

3. Mitsilegas $V$. The evolving EU anti-money laundering regime. Challenges for fundamental rights and rule of law // Maastricht Journal of European and Comparative Law. Vol. 23 (2): 33. April 1, 2016.

4. Perula J. The European Union's anti-money laundering crusade - a critical analysis of the responses by the EU/EC to money laundering // Reports of the Police College of Finland 83/2019. Tampere. 2009.

Материал поступил в редакцию 24 июля 2019 г.

\section{REFERENCES (TRANSLITERATION)}

1. Borlini L., Montanaro F. The Evolution of the EU law against criminal finance: the «hardening» of FATF Standards within EU // Georgetown Journal of International Law, 2017; Bocconi Legal Studies Research Paper No. 3010099.

2. Haffke L., Fromberger M., Zimmermann P. Cryptocurrencies and anti-money laundering: the shortcomings of the fifth AML Directive (EU) and how to address them // Journal of Banking Regulation, 2019.

3. Mitsilegas V. The evolving EU anti-money laundering regime. Challenges for fundamental rights and rule of law // Maastricht Journal of European and Comparative Law. Vol. 23 (2): 33. April 1, 2016.

4. Perula J. The European Union's anti-money laundering crusade - a critical analysis of the responses by the EU/EC to money laundering // Reports of the Police College of Finland 83/2019. Tampere. 2009. 